\title{
Long-term potentiation at the lateral perforant path-nucleus accumbens synapse in the rat in vivo
}

\author{
ALFREDO QUIÑONES-HINOJOSA \\ Harvard University, Boston, Massachusetts \\ BRIAN E. DERRICK and EDWIN J. BAREA-RODRIGUEZ \\ University of Texas, San Antonio, Texas \\ PATRICIA H. JANAK \\ National Institute on Drug Abuse, Baltimore, Maryland \\ and \\ JOE L. MARTINEZ, JR. \\ University of Texas, San Antonio, Texas
}

\begin{abstract}
The nucleus accumbens (NAcb), a basal forebrain structure implicated in drug-mediated reward, receives afferents from a variety of limbic and cortical structures, including the prefrontal cortex, the amygdala, the entorhinal cortex, and the subicular complex. In the present study, monosynaptic projections from the lateral entorhinal cortex (lateral perforant path) to the NAcb are shown to display sustained increases in field EPSP magnitudes following high-frequency stimulation of the perforant path in anesthetized rats. By contrast, stimulation of the medial aspect of the perforant path, although capable of evoking responses in the dentate gyrus, produced no observable synaptic responses within the nucleus accumbens. Intra-accumbens administration of ( \pm )-CPP (-3-(2-carboxypiperazin-4-yl)-propyl1-phosphonic acid), a selective competitive NMDA-receptor antagonist, blocked both short-term potentiation and long-term potentiation (LTP). Thus afferents from the entorhinal cortex to the NAcb display NMDA-receptor-dependent synaptic potentiation that appears similar to NMDA-receptordependent LTP observed at other targets of the perforant path, such as the hippocampal formation.
\end{abstract}

Long-term synaptic potentiation (LTP) is an intensively studied model of a cellular mechanism of synaptic plasticity that may underlie learning and memory processes (Bliss \& Lomo, 1973; Martinez \& Derrick, 1996). LTP is a persistent increase in the amplitude of synaptic responses following frequency-specific activation of afferent fibers. The existence of LTP in brain structures implicated in learning and memory, such as the hippocampus, and the parallels observed with pharmacological manipulations that can affect both LTP and learning, together support the hypothesis that LTP is a viable candidate for one cellular mechanism that may underlie learning and memory in the vertebrate nervous system (Martinez \& Derrick, 1996).

The nucleus accumbens (NAcb) is a basal forebrain structure that is thought to play an important role in the behavioral expression of drug self-administration (Koob \& Bloom, 1988). There is strong evidence that the NAcb has a critical role in both the locomotor and the rewarding effects of drugs that have abuse potential in humans, including both opiates and psychostimulants (Swerdlow \&

\footnotetext{
Supported by DA04195 to J.L.M. This research was conducted in the Department of Psychology, University of California, Berkeley. Correspondence should be addressed to $\mathbf{J}$. L. Martinez, Jr., Division of Life Sciences, University of Texas, San Antonio, TX 78240 (e-mail: jmartinez@utsa.edu).
}

Koob, 1984; see Koob, 1992, and Koob \& Bloom, 1988 for reviews).

The NAcb receives afferents from many cortical and limbic structures, such as the amygdala, the hippocampus lateral septum, the entorhinal cortex (EC) and the prelimbic cortex (Brog, Salyapongse, Deutch, \& Zahm, 1993; Meredith, Pennartz, \& Groenewegen, 1993). Afferents from the EC project primarily to medium spiny neurons of the both the core and the shell region of the NAcb, and activation of these afferents elicit excitatory effects (Finch, Gigg, Tan, \& Kosoyan, 1995) that are thought to be mediated by glutamate (Brog et al., 1993; Finch et al., 1995). Cortical association areas ultimately project to the $\mathrm{EC}$ (Swanson \& Kohler, 1986), which, in turn, project to hippocampus, amygdala, and the NAcb. Thus, highly processed, polysensory information is directed to the NAcb directly from the $\mathrm{EC}$, and indirectly via the hippocampus and amygdala.

Learning has been demonstrated to play an important role in maintaining addictive behaviors (Koob \& Bloom, 1988; Stolerman, 1992). In particular, associations between the rewarding effects of drugs and cues, including both single cues and the configuration of complex environmental cues, are thought to play an important role in a variety of behaviors associated with drug dependence, including drug-seeking behaviors in animals (Wise, 1988) 
and drug craving in humans (Stolerman, 1992; Wise, 1988). Thus LTP could be one cellular process mediating the association of external cues with the rewarding effects of drugs. In this view, plastic processes in afferents of the NAcb may contribute to learning associated with addiction, such as drug-seeking behaviors and selfadministration (Koob \& Bloom, 1988; Stolerman, 1992; White \& Milder, 1992; Wise, 1988).

Previous studies have demonstrated long-lasting increases in synaptic efficacy in several afferent systems to the NAcb, including those present in the external capsule and those from the hippocampal subicular complex via the fornix (Feasey-Truger \& ten Bruggencate, 1994; Kombian \& Malenka, 1994; Mulder, Arts, \& Lopes de Silva, 1997; Pennartz, Ameerun, Groenewegen, \& Lopes de Silva, 1993; Walsh \& Dunia, 1993). These projections display potentiation that is dependent on the activation of the $N$-methylD-aspartate (NMDA) type glutamate receptor, suggesting that potentiation of synaptic responses is similar to LTP observed in hippocampal and neocortical regions (FeaseyTruger \& ten Bruggencate, 1994; Kombian \& Malenka, 1994). Plasticity in NAcb afferents has been observed both in vivo and in vitro. In vitro studies of the NAcb have demonstrated several types of synaptic plasticity in the NAcb, including LTP, short-term potentiation (STP), and long-term depression (LTD; Pennartz et al., 1993). However, in these in vitro studies, stimulation of the external capsule or the overlying white matter present within a slice core of the NAcb is often employed. Because these fiber systems contain NAcb afferents originating from a number of cortical sources, it is uncertain which afferent systems contribute to NAcb responses observed in these in vitro studies (Kombian \& Malenka, 1994; Pennartz et al., 1993; Walsh \& Dunia, 1993). This makes assessment of the characteristics of NAcb potentiation difficult because it is known that different afferent systems can display different mechanisms of LTP induction, including NMDA-receptor-dependent and NMDA-receptor-independent forms (Johnston, Williams, Jaffe, \& Gray, 1992; Martinez \& Derrick, 1996). Thus isolation of specific afferent systems is crucial for identifying different mechanisms of plasticity in the various afferent systems of the NAcb. For this reason, the use of in vivo methods is of utility in that it allows for relatively selective stimulation of specific afferents within the intact brain (Feasey-Truger \& ten Bruggencate, 1994; Mulder et al., 1997).

Recent studies using intact animals indicate that an LTP following high-frequency stimulation can be observed both in fimbrial and subicular afferents of the NAcb. LTP of NAcb responses evoked by hippocampal stimulation in vivo is sensitive to NMDA-receptor antagonists (Feasey-Truger \& ten Bruggencate, 1994). However, it remains to be demonstrated whether direct projections from the EC to the NAcb display synaptic potentiation and whether such potentiation is sensitive to NMDA-receptor antagonists. The experiments presented here focus on potentiation in $\mathrm{EC}$-perforant path projections to the NAcb and whether these projections display
LTP induction that is dependent on the activation of NMDA receptors. Some of these data were reported previously in preliminary form (Quiñones-Hinojosa, Derrick, Barea-Rodriguez, Janak, \& Martinez, 1994).

\section{METHOD}

Male Sprague-Dawley rats (Simonsen, Gilroy, CA) weighing $350-400 \mathrm{~g}$ on arrival were housed individually in accordance with NIH guidelines. Animal use procedures were approved in advance by the Institutional Animal Care and Use Committee at the University of California at Berkeley.

Animals were anesthetized by an intraperitoneal injection of $64 \mathrm{mg} / \mathrm{kg}$ sodium pentobarbital and maintained at a surgical level of anesthesia with hourly booster injections of pentobarbital $(12 \mathrm{mg} / \mathrm{kg} / \mathrm{h})$. Body temperature was maintained at $37^{\circ} \mathrm{C}$. Using stereotaxic coordinates (Paxinos \& Watson, 1983), electrodes were placed in the angular bundle ( $-8.1 \mathrm{~mm} \mathrm{AP,} 4.1 \mathrm{~mm} \mathrm{ML})$, the dentate gyrus $(-3.0 \mathrm{~mm} \mathrm{AP},-2.0 \mathrm{~mm} \mathrm{ML})$, and the lateral core of the NAcb (+1.9 mm AP, $-1.9 \mathrm{~mm} \mathrm{ML})$. A stimulating bipolar electrode made of twisted, Teflon-coated stainless steel wires was used to deliver constant-current stimulation (20-350 $\mu \mathrm{A}$ monophasic pulses, $0.2-0.25$ msec duration) provided by a Grass $\mathrm{S} 48$ stimulator and delivered via a Grass P6 stimulus isolation unit. A single stainless steel wire (0.007-in. diameter; A-M system) served as a monopolar recording electrode and was placed in the core of the NAcb. In animals to which drug was delivered locally to the recording sites, a 29-gauge stainless steel epoxy-coated cannula exposed only at the tip was used as a recording electrode. Extracellular recordings were referenced to a stainless steel screw placed on the surface of the skull, amplified by a Grass P5 series, AC preamplifier, filtered $(0.3-10 \mathrm{~Hz})$, and then stored for off-line analysis using DataWave software (Thornton, $\mathrm{CO}$ ).

The EC can be divided into a lateral and a medial component on the basis of cytoarchitectonic (Hjorth-Simonsen \& Jeune, 1972) and physiological methods (McNaughton, 1980; McNaughton \& Barnes, 1977). Anatomical evidence suggests that both the medial and lateral aspects of the EC project to the NAcb and the dentate gyrus in a topographic manner (Amaral \& Witter, 1995; Bayer, 1985; Brog et al., 1993; Totterdell \& Meredith, 1997). Because afferents of the medial and lateral EC remain segregated within the perforant path at the angular bundle, these afferents can be stimulated selectively. Responses evoked by stimulating either the medial perforant path (MPP) or the lateral perforant path (LPP) within the angular bundle and recording within the hippocampal formation have been well defined (Breindl, Derrick, Rodriguez, \& Martinez, 1994; McNaughton, 1980; McNaughton \& Barnes, 1977). Therefore, sites within the angular bundle eliciting a maximal MPP or LPP response were first obtained by recording from the dentate gyrus. The recording electrode was placed into the granule cell layer of the dentate gyrus, as determined by both stereotaxic coordinates and injury-induced unit discharges of the dentate granule cells. The stimulating electrode was then lowered into the medial and lateral aspect of the angular bundle (dorsoventral depth, 2.5-3.0 for MPP and 3.2-3.6 for LPP). Once maximal responses were observed in the dentate gyrus, the recording electrode was moved to the lateral region of the NAcb. The stimulating electrode remained at the location where it evoked a maximal response within the dentate gyrus.

At the start of each experiment, maximal responses (peak of field EPSP) for each animal were evoked using up to $800 \mu \mathrm{A}$ of current. The current intensity eliciting a $50 \%$ maximal response was determined and used for all subsequent low-frequency stimulation. Lowfrequency responses were then evoked at a rate of $0.066 \mathrm{~Hz}$. Experimental manipulations began following collection of at least $30 \mathrm{~min}$ of baseline responses. 
A

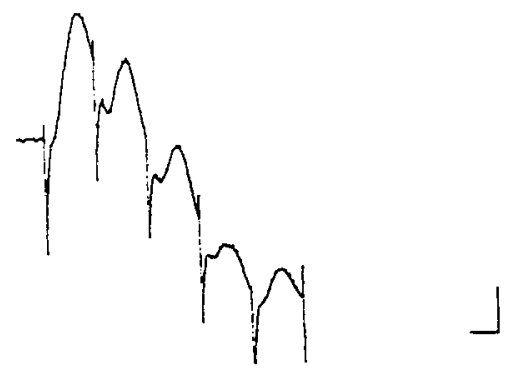

B

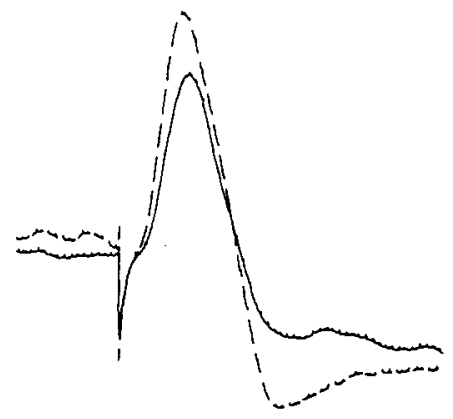

Figure 1. (A) Characteristic LPP-NAcb responses evoked in vivo. Stimulation of the lateral perforant path (LPP) evoked a response in the nucleus accumbens (NAcb) that followed highfrequency $(100-\mathrm{Hz})$ stimulation. Calibration $0.5 \mathrm{mV}, 1 \mathrm{msec}$. (B) Comparison of the LPP-NAcb evoked response before tetanization (solid line) and after tetanization (dotted line) in the presence of lactated Ringer's vehicle. The LPP-NAcb responses displayed potentiation following high-frequency stimulation, as indicated by the increase in the field EPSP slope. Calibration $.25 \mathrm{mV}, 1 \mathrm{msec}$.

Drugs were prepared in lactated Ringer's solution prior to each experiment. Drugs were applied at a volume of $1.0 \mu \mathrm{l}$ and delivered via micropressure ejection through a cannula. The NMDA receptor antagonist ( \pm )-CPP (-3-(2-carboxypiperazin-4-yl)-propyl-1-phosphonic acid) (1 or $10 \mathrm{nmol})$ or the lactated Ringer's vehicle was administered directly into the NAcb at a rate of $0.20 \mu \mathrm{l} / \mathrm{min}$ (1- $\mu 1$ volume). Following completion of drug administration, responses were collected for an additional $20 \mathrm{~min}$. Five $100-\mathrm{Hz} \mathrm{l}-\mathrm{sec}$ trains (intertrain interval of $15 \mathrm{sec}$ ) were applied $20 \mathrm{~min}$ following drug application using the current intensity that elicited the maximum field EPSP amplitude. EEG was monitored in the NAcb during tetanus, and no animals displayed afterdischarges following tetanization.

Response magnitudes were measured using the slope of the field EPSP within the 3-msec period following response onset. LTP magnitude is expressed as the percent increase in the field EPSP slope of postconditioning train responses recorded between 1-5, 15-20, and 55-60 min posttetanus as compared with the average magnitude of responses recorded $20 \mathrm{~min}$ prior to tetanus. Treatment effects were evaluated using a single- $d f$ analysis of variance (ANOVA; Keppel \& Zedeck, 1991).

\section{RESULTS}

Depth profiles of NAcb responses evoked by stimulation of the extreme dorsomedial or ventrolateral aspects of the angular bundle revealed that only stimulation of the lateral aspect in the anesthetized rat in vivo evoked a population EPSP response, a finding consistent with reports indicating that the lateral shell region of the NAcb is innervated primarily by LPP fibers (Totterdell \& Meredith, 1997). This response was characterized by an early positive-going component that appeared as the recording electrode entered the lateral NAcb, an observation consistent with previous reports suggesting that because LPP afferents terminate in dendritic regions of the lateral shell (Totterdell \& Meredith, 1997), the core of the NAcb behaves effectively as a weak current source (see Lopes de Silva, Arnolds, \& Neijt, 1984). The positive-going response elicited by LPP stimulation had an onset of 1-2 msec, a peak at 4-5 msec, and an amplitude range of $0.4-1.0 \mathrm{mV}$ (Figure 1). In addition, LPP-NAcb responses could follow 100-Hz stimulation (Figure 1A). By contrast, stimulation of the MPP at sites eliciting robust responses in the dentate gyrus yielded no observable responses within the NAcb (data not shown). That both MPP and LPP stimulation evoked robust responses in the dentate gyrus, but only LPP stimulation elicited observable NAcb responses, and that effects were observed with drugs administered locally in the NAcb (see below) together suggest that LPP stimulation evoked responses in the NAcb that were locally generated and not the result of volume conduction from the dentate gyrus.

Application of the 1- $\mu 1$ quantity of the lactated Ringer's vehicle did not alter evoked LPP-NAcb responses as measured 15-20 min following cessation of delivery $[F(1,8)=0.72, p>.05, M \pm S E M, n=5]$. Twenty min after application of lactated Ringer's vehicle, high-frequency stimulation produced an immediate increase in both slope and peak amplitudes of LPP-NAcb responses (Figure 1B, Figure 2). The mean increase in the EPSP slope $1-5$ and $15-20 \mathrm{~min}$ posttetanization was $+45 \pm 11 \%$ and $+45 \pm 6 \%$, respectively (Figure 2 ). The potentiation of NAcb responses was decremental, and, when measured $1 \mathrm{~h}$ posttetanization, the increase in the EPSP slope was $+31 \pm 12 \%$.

Application of a $1-\mu 1$ volume of either a $1-$ or $10-\mathrm{nmol}$ quantity of the NMDA-receptor antagonist $( \pm)$-CPP did not alter significantly the magnitude of evoked LPP-NAcb responses as measured 15-20 min following cessation of drug delivery $[1 \mathrm{nmol}, F(1,8)=0.99, p>.05,10 \mathrm{nmol}$, $F(1,8)=0.29, p>.05$; Figures $2 \mathrm{~A}$ and $2 \mathrm{~B}]$.

A significant dose-dependent effect of ( \pm )-CPP on the magnitude of STP was observed as a result of pretreatment with $( \pm)$-CPP. Only the 10 -nmol quantity of $( \pm)$-CPP attenuated significantly the magnitude of STP of LPP-NAcb responses when measured 1-5 min posttetanus as compared with the lactated Ringer's controls (Figures 2B and 3A). By contrast, both the 1- and 10nmol quantities of ( \pm$)$-CPP attenuated STP measured 15-20 min posttetanus as compared with the lactated Ringer's controls (Figure 3B).

The magnitude of LTP as a result of pretreatment with ( \pm )-CPP was also altered in a dose-dependent manner. Although both the $1-$ and 10 -nmol quantities of ( \pm -CPP 
LEC to Acb Long-Term Potentiation: Ringer's vs. CPP (1nM)

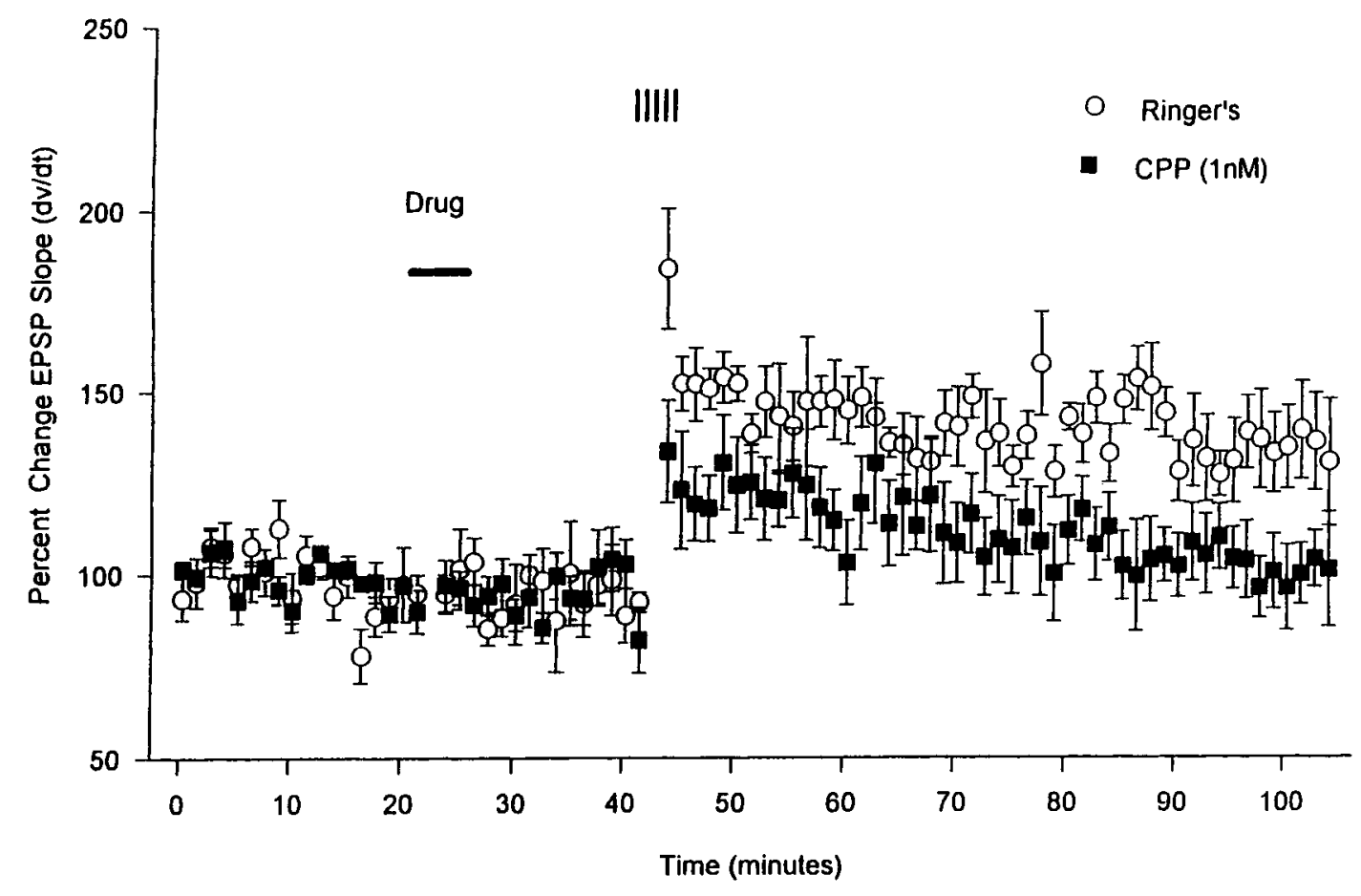

LEC to Acb Long-Term Potentiation: Ringer's vs. CPP (10 nM)

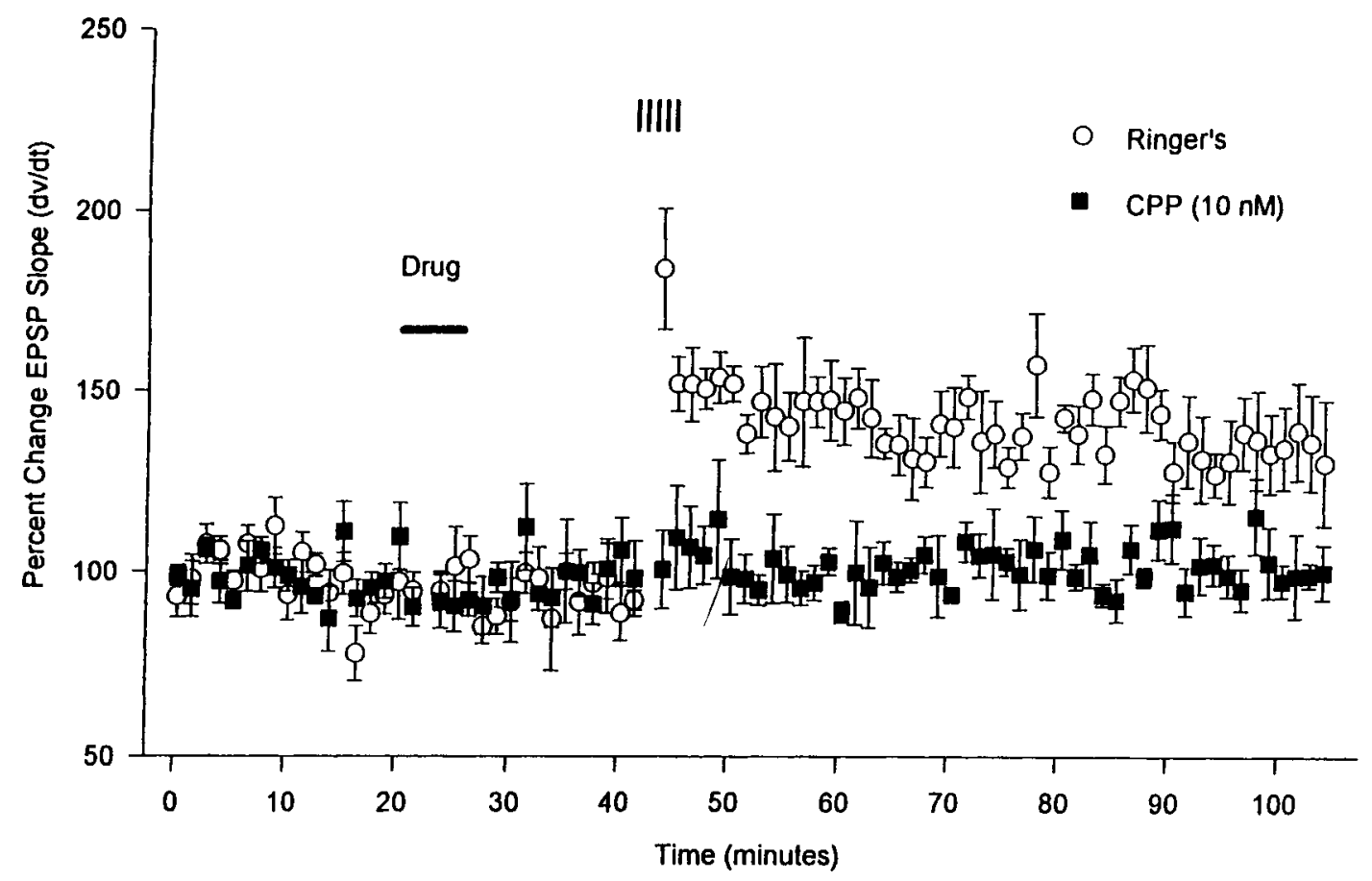

Figure 2. LPP-NAcb responses display NMDA-receptor-dependent synaptic potentiation following highfrequency stimulation. Point plots of LPP-NAcb field EPSP slope magnitudes following local delivery of the lactated Ringer's vehicle and either (A) $1 \mathrm{nmol}( \pm)$-CPP, or (B) 10-nmol quantity of ( \pm )-CPP. LPP, lateral perforant path; NAcb, nucleus accumbens; CPP, (-3-(2-carboxypiperazin-4-y1)-propyl-1-phosphonic acid). 
attenuated the magnitude of LTP as measured at $60 \mathrm{~min}$, a significant attenuation of LPP-NAcb LTP was observed only with a 10 -nmol quantity of $( \pm)$-CPP compared with animals receiving the lactated Ringer's vehicle $[F(1,8)=$ $5.83, p<.05$; Figure $3 \mathrm{C}]$. The attenuation of LTP at $55-60$ min posttetanus by the 1 -nmol quantity of ( \pm -CPP was not significant $[F(1,8)=3.82, p>.05$, Figure $3 \mathrm{~B}]$.

\section{DISCUSSION}

The observation that LPP-NAcb evoked responses displayed both short onset latencies and the ability to follow high-frequency trains (McNaughton and Barnes, 1977 , Figure b), along with the observation that LPP, but not MPP stimulation elicited responses in the NAcb despite the fact that both LPP and MPP stimulation elicited responses in the dentate gyrus, indicates that stimulation of the lateral, but not the medial, EC/perforant path fibers evoked a locally generated monosynaptic response in the NAcb. This is consistent with anatomical studies indicating projections primarily from the lateral EC to the NAcb (Bayer, 1985).

The principal findings in this study demonstrate that responses elicited by stimulation of the lateral aspect of the perforant path display STP and LTP induction that is sensitive to NMDA receptor antagonists. High-frequency stimulation of LPP afferents led to a decremental potentiation of LPP-NAcb field EPSP responses. STP was also blocked by local application of the NMDA-receptor antagonist $( \pm)$-CPP into the NAcb. This blockade was dose dependent in that the 10-nmol quantity, but not the 1-nmol quantity of $( \pm)$-CPP, was effective, whereas all doses of $( \pm)$-CPP blocked the induction of LTP as measured 55-60 min posttetanus. Although LTP in the NAcb has been described previously (Pennartz et al., 1993), the findings in the present study provide the first demonstration of NMDA-receptor-dependent potentiation in monosynaptic EC projections to the NAcb in vivo.

LTP of EC-NAcb afferents appeared to be short lived (usually less than $2 \mathrm{~h}$, data not shown). However, because the duration of LTP can depend upon a variety of factors, including both stimulation parameters and the intensity of stimulation (Bliss \& Collingridge, 1993), and because LPP stimulation elicits only modest $(0.5-\mathrm{mV})$ response in the NAcb as compared with fimbrial-NAcb responses (Quiñones-Hinojosa et al., 1994), the observation of only a decremental potentiation may be a consequence of limited levels of postsynaptic activation. In future studies, it will be necessary to determine whether decremental potentiation is characteristic of LTP in this afferent system or whether more sustained depolarization may produce longer lived, nondecremental forms of LTP.

High-frequency stimulation of a number of NAcb afferent systems elicits a number of synaptic phenomena, including LTP, decremental potentiation (STP), and LTD (Boeijinga, Mulder, Pennartz, \& Manshanden, 1993; Feasey-Truger \& ten Bruggencate, 1994; Mulder, Arts, \& Lopes de Silva, 1993; Pennartz et al., 1993; Quiñones-
Hinojosa et al., 1994; Walsh \& Dunia, 1993). Different afferent systems to the NAcb display activity-induced plasticity with distinct characteristics. For example, highfrequency stimulation of glutamatergic afferents originating from the fornix (Boeijinga et al., 1993) or callosal fibers (Walsh \& Dunia, 1993) produces a decremental potentiation similar to the decremental potentiation reported here for the perforant path afferent system in vivo (Pennartz et al., 1993; Quiñones-Hinojosa et al., 1994). By contrast, high-frequency stimulation of the lateral amygdala in vivo elicits a slowly developing (slow-onset) potentiation of NAcb responses (Quiñones-Hinojosa et al., 1994). Thus the characteristics of LTP in the NAcb depend on the particular afferent system that is stimulated. Because many of the previous in vitro studies elicited NAcb responses via stimulation of heterogenous fiber pathways (such as white matter within the internal capsule), and because many afferent systems to the NAcb project via the internal capsule (including those from the fornix, amygdala, and frontal cortex; Bayer, 1985), it is likely that stimulation of heterogenous fiber systems as performed in many in vitro studies evoke potentiation from a variety of afferents. Thus the in vivo preparation is likely to be of greater utility in assessing the varieties of plasticity observed in the various afferent systems of this nucleus.

NMDA-receptor-dependent LTP is thought to be a primary candidate for one cellular mechanism underlying associative learning (Martinez \& Derrick, 1996). Associations between the rewarding effects of drugs and sensory cues, including both single cues and the complex configurations of cues within the environment, are thought to play an important role in behaviors associated with drug dependence, including drug-seeking behaviors in animals (Wise, 1988) and drug craving in humans (Stolerman, 1992; Wise, 1988). Thus the various plastic phenomena observed between the NAcb and limbic structures implicated in memory may be an important process mediating the association of external cues with the rewarding effects of drugs.

The structures and projections involved in different forms of learning that signal drug reward are only now being addressed experimentally. The hippocampus and amygdala are thought to be structures essential in learning associated with drug reward. Each of these structures receives highly processed sensory inputs from the EC. Thus entorhinal afferents to limbic structures that project to the NAcb also are likely to be important for learning that couples a variety of external stimuli with drug reward. However, the necessity of each structure depends on the type of learning involved. For instance, damage to the hippocampus or amygdala can impair learning associated with complex or affective cues, whereas damage to either hippocampus or amygdala does not alter reinforced stimulus-response associations (McDonald \& White, 1993). Thus direct entorhinal afferents to the NAcb could be important for learning that couples external cues with drug reward. Further studies of LTP-like phenomena in the various projections to the NAcb may re- 
A

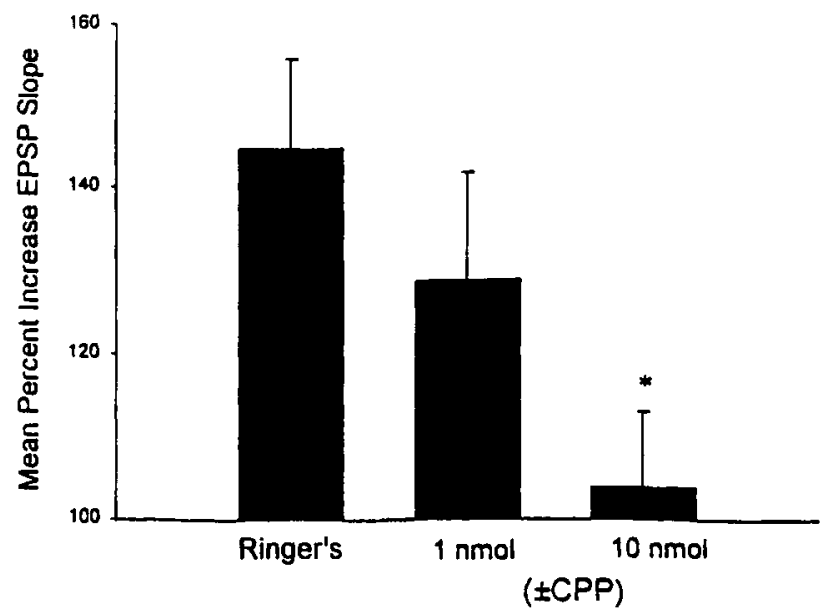

B

$15-20 \mathrm{~min}$

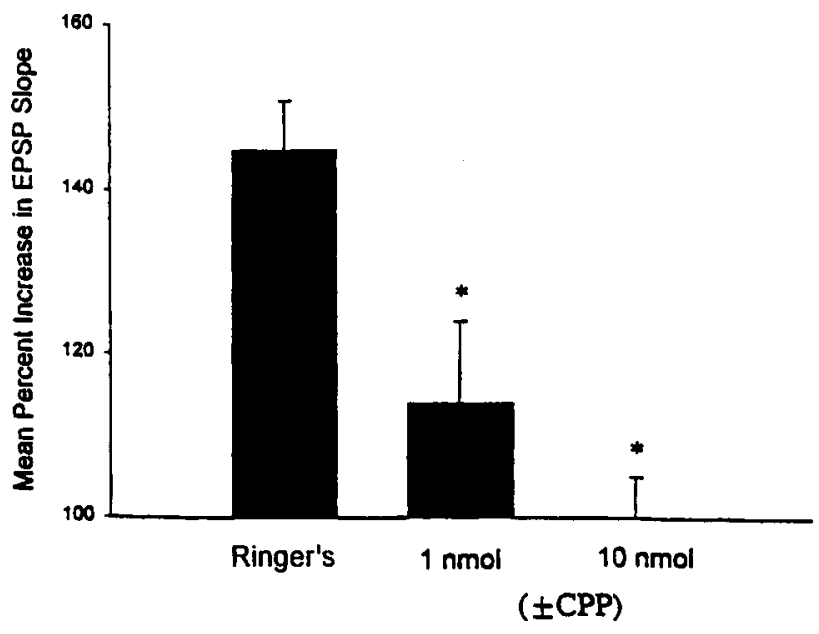

C

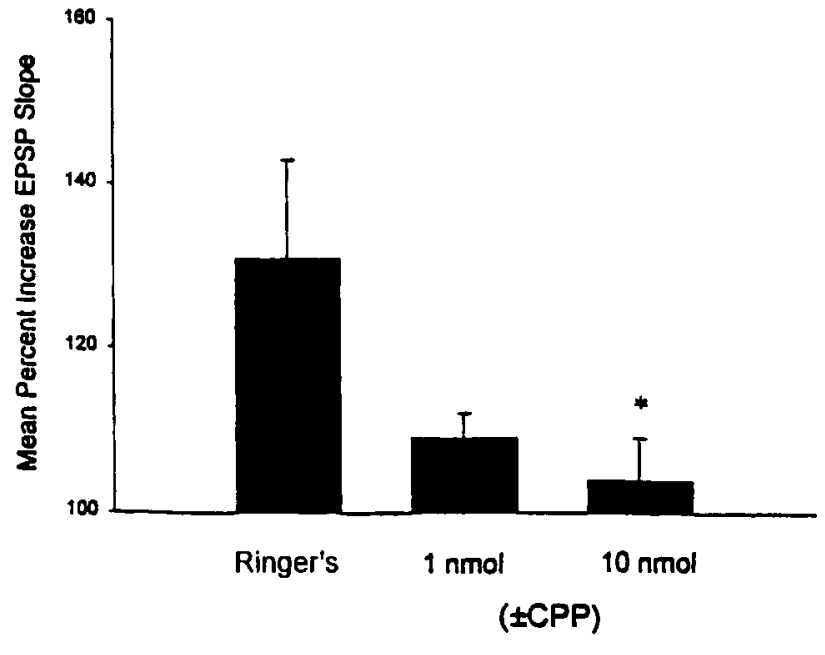

Figure 3. Dose-response of 1 and $10 \mathrm{nmol}$ of ( \pm )-CPP and the lactated Ringer's vehicle on short-term potentiation (STP) and long-term potentiation (LTP) of LPP-NAcb responses as measured 1-5 min (A), 15-20 $\mathrm{min}(B)$, and 55-60 $\mathrm{min}(\mathrm{C})$ posttetanus, respectively. Only the 10-nmol quantities of $( \pm)$-CPP produced a significant decrease in the magnitude of STP as measured at 1-5 min, and the magnitude of LTP as measured at 55-60 min. Both the 1- and 10-nmol quantities of ( \pm )CPP altered significantly the magnitude of LPP-NAcb STP as measured at 15-20 min ( $\left.{ }^{*}<-05\right)$. LPP, Lateral perforant path; NAcb, nucleus accumbens; CCP, (-3-(2-carboxypiperazin-4-y1-phosphoric acid). 
veal the structures involved in specific types of learning and may provide a useful model for the synaptic plasticity and learning thought to be essential for maintaining addictive behaviors.

\section{REFERENCES}

Amaral, D. G., \& Witter, M. P. (1995). Hippocampal formation. In G. Paxinos (Ed.), The rat nervous system (2nd ed., pp. 443-493). San Diego: Academic Press.

BAYER, S. A. (1985). Hippocampal region. In G. Paxinos (Ed.), The rat nervous system (Vol. 1, pp. 335-352). San Diego: Academic Press.

Bliss T. V. P., \& Collingridge G. L. (1993). A synaptic model of memory: Long-term potentiation in the hippocampus. Nature, 361, 31-39.

BLISs, T. V. P., \& LoMo, T. (1973). Long-lasting potentiation of synaptic transmission in the dentate area of the anaesthetized rabbit following stimulation of the perforant path. Journal of Physiology, 232, 331-356.

Boeijinga, P. H., Mulder, A. B., Pennartz, C. M. A., \& ManshanDEN, I. (1993). Responses of the NAcb following fornix-fimbria stimulation in the rat--Identification and long-term potentiation of monosynaptic and polysynaptic pathways. Neuroscience, 53, 1049-1058

Breindl, A., Derrick, B. E., Rodriguez, S. B., \& Martinez, J. L., JR. (1994). Opioid receptor-dependent long-term potentiation at the lateral perforant path-CA3 synapse in rat hippocampus. Brain Research Bulletin, 33, 17-24

Brog, J. S., Salyapongse, A., Deutch, A. Y., \& Zahm, D. H. (1993) The patterns of afferent innervation of the core and shell in the "accumbens" part of the rat ventral striatum: Immunohistochemical detection of retrogradely transported fluoro-gold. Journal of Comparative Neurology, 338, 255-278.

Feasey-Truger, K. J., \& ten Bruggencate, G. (1994). The NMDA receptor antagonist $( \pm)$-CPP suppresses long-term potentiation in the rat hippocampal-accumbens pathway in vivo. European Journal of Neuroscience, 6, 1247-1254.

Finch, D. M., Gigg, J., Tan, A. M., \& Kosoyan, O. P. (1995). Neurophysiology and neuropharmacology of projections from entorhinal cortex to striatum in the rat. Brain Research, 670, 233-247.

HJORTH-SimonsEN, A., \& JEUNE, B. (1972). Origin and termination of the hippocampal perforant path in the rat studied by silver impregnation. Journal of Comparative Neurology, 144, 215-232.

Johnston, D., Williams, S., JafFe, D., \& Gray, R. (1992). NMDA receptor-independent long-term potentiation. Annual Review of Physiology, 54, 489-505.

KEPPEL, G., \& ZEDECK, S. (1991). Data analysis for research design. Englewood Cliffs, NJ: Prentice-Hall.

Kombian, S. B., \& MaLENKA R. C. (1994). Simultaneous LTP of nonNMDA- and LTD of NMDA-receptor-mediated responses in the nucleus accumbens. Nature, 368, 242-246.

KOOB, G. F. (1992) Drugs of abuse: Anatomy, pharmacology and function of reward pathways. Trends in Pharmacological Sciences, 13, 177-184.

КоOB, G. F., \& BLOOM, F. E. (1988). Cellular and molecular mechanisms of drug dependence. Science, 242, 715-723.

Lopes de Silva, F. H., ARnolds, D. E., \& Neitu, H. C. (1984). A functional link between the limbic cortex and ventral striatum: Physiol- ogy of the subiculum accumbens pathway. Experimental Brain Research, 55, 205-214.

Martinez, J. L., JR., \& DeRrick, B. E. (1996). Long-term potentiation and learning. Annual Review of Psychology, 47, 173-203.

MCDonald, R. J., \& White, N. M. (1993). A triple dissociation of memory systems: Hippocampus, amygdala and dorsal striatum. Behavioral Neuroscience, 107, 3-22.

MCNaUghton, B. L. (1980). Evidence for two physiologically distinct perforant pathways to the fascia dentata. Brain Research, 199, 1-19.

McNaughton, B. L., \& Barnes, C. A. (1977). Physiological identification and analysis of dentate granule cell responses to stimulation of the medial and lateral perforant pathways in the rat. Journal of Comparative Neurology, 175, 439-454.

Meredith, G. E., Pennartz, C. N. A., \& Groenewegen, H. J. (1993). The cellular framework for chemical signaling in the nucleus accumbens. Progress in Brain Research, 99, 3-24.

Mulder, A. B., ARTs, M. P. M., \& Lopes de Silva, F. H. (1993). Longterm potentiation simultaneously elicited in hippocampus, nucleus accumbens and frontal cortex. Neuroscience Research Communications, 13(Suppl. 1), S11-S14.

Mulder, A. B., Arts, M. P. M., \& Lopes de Silva, F. H. (1997). Shortand long-term plasticity of the hippocampus to nucleus accumbens and prefrontal cortex pathways in the rat in vivo. European Journal of Neuroscience, 9, 1603-1611.

Paxinos, G., \& Watson, C. (1983). Stereotaxic atlas of the rat brain. New York: Academic Press.

Pennartz, C. M., Ameerun, R. F., Groenewegen, H. J., \& Lopes de SILVA, F. H. (1993). Synaptic plasticity in an in vitro slice preparation of the rat nucleus accumbens. European Journal of Neuroscience, $\mathbf{5}$, $107-117$.

Quiñones-Hinojosa, A., Derrick, B. E., Barea-Rodriguez, E. J., JANAK, P. H., \& MARTINEZ, J. L., JR. (1994). LTP and LTD in four afferent systems of the rat nucleus accumbens in vivo. Society for $\mathrm{Neu}$ roscience Abstracts, $20,898$.

STOLERMAN, I. (1992). Drugs of abuse: behavioural principles, methods and terms. Trends in Pharmacological Science, 13(5), 170-176.

SWANSON, L. W., Kohler, C. (1986). Anatomical evidence for direct projections from the entorhinal area to the entire cortical mantle in the rat. Journal of Neuroscience, 6, 3010-3023.

SwerdLow, N. R. A., \& KоOB, G. F. (1984). The neural substrates of apomorphine-stimulated locomotor activity following enervation of the nucleus accumbens. Life Sciences, 35, 2537-2544.

TotTerdell, S., \& Meredith, G. E. (1997). Topographical organization of projections from the entorhinal cortex to the striatum of the rat. Neuroscience, 78, 715-729.

WALSH, J. P., \& DUNIA, R. (1993). Synaptic activation of NMDA receptors induces short-term potentiation at excitatory synapses of the striatum in rats. Neuroscience, 57, 241-248.

White, N. M., \& MiLder, P. M. (1992). The psychobiology of reinforcers. Annual Review of Psychology, 43, 443-471.

WISE, R. A. (1988). The neurobiology of craving: Implications for the understanding and treatment of addiction. Journal of Abnormal Psychology, 97, 118-132.

(Manuscript received August 25, 1997; revision accepted for publication March 11, 1998.) 